\title{
Counting crayfish: active searching and baited cameras trump conventional hoop netting in detecting Euastacus armatus
}

\author{
Christopher J. Fulton ${ }^{1, *}$, Danswell Starrs ${ }^{1}$, Monica P. Ruibal ${ }^{1}$, Brendan C. Ebner ${ }^{2}$ \\ ${ }^{1}$ Evolution, Ecology \& Genetics, Research School of Biology, The Australian National University, Canberra, \\ ACT 2601, Australia \\ ${ }^{2}$ Tropical Landscapes Joint Venture, CSIRO Ecosystem Sciences \& TropWATER, James Cook University, PO Box 780, \\ Atherton, QLD 4883, Australia
}

\begin{abstract}
Accurate distribution and abundance estimates for rare and endangered species are necessary to ascertain extinction threats and take appropriate conservation measures. Traditional capture-based methods are imperfect for surveying elusive species such as freshwater crayfish in upland streams. We compared estimates of Murray River crayfish Euastacus armatus abundance made via direct visual assessments by snorkel, against baited remote underwater video surveys (BRUVS) and traditional hoop netting conducted in 2 montane river systems. Similar total abundances were recorded via visual survey and BRUVS across 4 sites within 1 river system where $E$. armatus was relatively common. In contrast, markedly lower values were obtained at these sites via conventional hoop netting methods. In another stream where E. armatus is particularly rare, the only detection of this species was via BRUVS. Average catch per unit effort (CPUE) was highest from active visual surveys (2.99 ind. $\mathrm{h}^{-1}$ ), followed by BRUVS (0.63) and hoop netting (0.13). Extremely low sampling efficiency from hoop netting was attributed to the short time periods crayfish attended baits (mean $\pm \mathrm{SE}, 387 \pm 209 \mathrm{~s}$ ) relative to the rate of net retrieval (hourly). We conclude that in systems of adequate water clarity, visual surveys and BRUVS provide reliable, non-invasive methods for estimating freshwater crayfish abundance and hold promise particularly for research and monitoring of threatened Euastacus species.
\end{abstract}

KEY WORDS: Visual census · Trapping $\cdot$ Monitoring $\cdot$ Sample estimates $\cdot$ Parastacidae $\cdot$ Rarity Resale or republication not permitted without written consent of the publisher

\section{INTRODUCTION}

Rare and endangered species are often highly sensitive to changes in their environment and susceptible to further population declines. Freshwater crayfish are considered to be one such vulnerable group, owing to their homotopic life history and sensitivity to environmental conditions and chemical pollutants (Geddes 1990, reviewed by Gilligan et al. 2007). Crucial to the classification and management of species considered vulnerable to extinction is our ability to obtain reliable and accurate population estimates, especially when changes in abundance affect detect- ability (McConville et al. 2009, Rayment et al. 2011). Likewise, we require reliable population estimates to discern the effectiveness of recovery or abatement actions (Clarke et al. 2003, Baker 2004, Shields 2004).

Several methods have been used to sample freshwater crayfish, such as baited traps and hoop nets, electrofishing, direct visual surveys, dip netting and seining. All of these survey methods involve some error that produces a biased sample of the population (Rabeni et al. 1997, Gladman et al. 2010). Bias occurs as a result of either the selectivity of the sampling gear for certain species, sexes and sizes, or variation in crayfish behaviour across seasons, habitat selec- 
tion, previous sampling interactions, predator avoidance and habitat type (Brown \& Brewis 1978, Somers \& Stechey 1986, Rabeni et al. 1997, Dorn et al. 2005, Ryan et al. 2008, Gladman et al. 2010). Relatively few crayfish studies have examined sampling efficiencies, and these have shown that some methods are prone to underestimating true population sizes (Brown \& Brewis 1978, Rabeni et al. 1997, Dorn et al. 2005, Gladman et al. 2010). In particular, baited trap methods have often been criticised for their ineffectiveness to quantitatively sample crayfish populations (Bean \& Huner 1978, Brown \& Brewis 1978, Somers \& Stechey 1986, Rabeni et al. 1997, Alonso 2001, Gladman et al. 2010), especially cryptic and highly elusive species such as those in the genus Euastacus. Euastacus encompasses 49 described species, of which $80 \%$ are threatened at some level relative to IUCN classification standards (Furse \& Coughran 2011a). Clearly, we must evaluate the efficiency of survey methods used to assess and monitor threatened crayfish species in order to obtain reliable population estimates.

We assess the effectiveness of 3 different methods for enumerating populations of the world's second largest freshwater crayfish, the Murray River crayfish Euastacus armatus. Over the past 6 decades, it has become apparent that E. armatus has dramatically declined in abundance, to the extent that the species has become locally extinct or extremely rare in some river reaches across the Murray-Darling River Basin due to a combination of habitat loss, pollution and overfishing (Gilligan et al. 2007, Furse \& Coughran $2011 b)$. In recognition of the decline of E. armatus, this species has been classified as Data Deficient internationally (IUCN 2011), and either threatened or vulnerable in 3 of the 4 Australian states/territories where it has historically been recorded (Australian Capital Territory Nature Conservation Act of 1980, Victoria Flora \& Fauna Guarantee Act of 1988, South Australia Fisheries Management Act of 2007). As such, there is an urgent need to collect distribution and abundance information for this species in a manner that is as accurate and efficient as possible, and one that has the capacity to detect such elusive species when they are low in abundance.

Monitoring programmes for large crayfish species like Euastacus armatus have typically used baited hoop nets as the primary survey technique (Gilligan et al. 2007, Furse \& Coughran 2011b), despite the well-known inefficiencies and sampling biases inherent to baited trap or net methods (Bean \& Huner 1978, Somers \& Stechey 1986, Rabeni et al. 1997, Gladman et al. 2010). A single brief study examined the effectiveness of baited methods for detecting E. armatus (McCarthy 2005), finding an approximately 2-fold difference in the rate of captures using hoop nets compared to Munyana traps (0.725 crayfish per hoop-net hour versus 0.408 crayfish per Munyana hour). However, McCarthy (2005) was unable to detect whether such trapping estimates were a true reflection of total crayfish population size in the sampling area. With such discrepancies, there is concern that traditional methods may overlook the presence of this elusive species where it is in low density, leading in turn to serious misrepresentations of its abundance, geographical range and conservation status.

We aimed to evaluate the efficiency of 2 novel visual survey methods, viz. baited remote underwater video surveys (BRUVS) and active searching by snorkel, in estimating the abundance of Euastacus armatus compared to traditional hoop netting techniques in upland river systems. Increasing evidence is pointing towards remote underwater video as being an effective means of detecting and recording the diversity, abundance and behaviour of aquatic organisms, particularly elusive or cryptic species (Bellwood et al. 2006, Fox \& Bellwood 2008, Ebner et al. 2009, Gucu 2009, Brooks et al. 2011, Harvey et al. 2012). We chose small montane rivers as the focal habitat, as these clear, high-flow systems have proved particularly challenging for traditional survey techniques. Moreover, montane river systems are home to the majority of freshwater crayfish species, both in the study region (41 species in New South Wales, McCormick 2008) and worldwide (540 species, Holdich 2002), with 50 to $60 \%$ of these species recently assessed as being of conservation concern (Taylor et al. 1996, Holdich 2002, Furse \& Coughran 2011a).

\section{MATERIALS AND METHODS}

Crayfish surveys were conducted across 4 sites within each of the Goobarragandra and Cotter rivers in southeast Australia (Fig. 1). The Goobarragandra River is a clear, narrow, freshwater montane river with a stony bottom consisting of a mixture of bedrock (mean of $6 \%$ cover), boulders (39\%), cobbles $(12 \%)$, pebbles $(6 \%)$, gravel $(17 \%)$, fines $(13 \%)$, leaf litter $(5 \%)$ and woody debris $(2 \%)$, based on 8 replicate $1 \mathrm{~m}^{2}$ surveys of benthic cover within each surveyed site. The Cotter River is a similar montane river, with the substratum at our sites consisting of bedrock (mean of $8 \%$ cover), boulders (32\%), cob- 


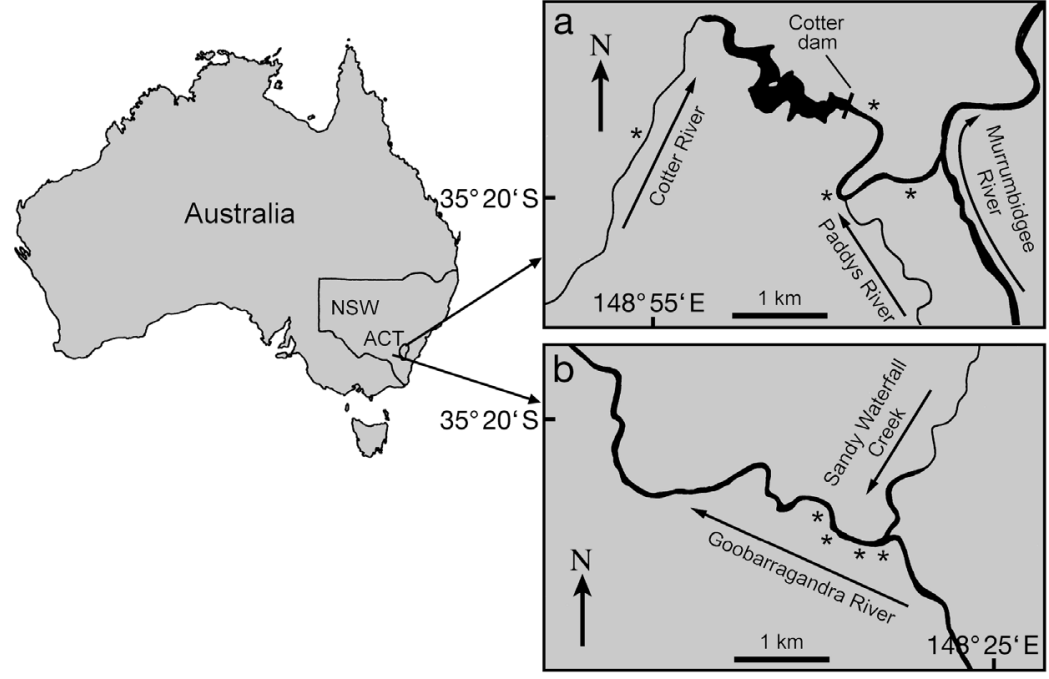

Fig. 1. Crayfish survey sites (*) on the (a) Cotter River, Australian Capital Territory (ACT), and (b) Goobarragandra River, New South Wales (NSW) in southeast Australia. Arrows indicate river flow direction

Active visual surveys involved 2 observers searching for crayfish by walking upstream on either side of the river channel. In deeper sections $(>50 \mathrm{~cm}$ ) of the river, observers swam in a zig-zag path while using masks and snorkels to spot crayfish individuals underwater, as described by Fulton et al. (2001). Time spent at each site was dependent on the size and complexity of the habitat, with a mean $( \pm \mathrm{SE})$ of $46.4 \pm 13.7 \mathrm{~min}$ spent by 2 observers actively searching at each site. All individuals were collected with hand nets and placed in different buckets during the survey to ensure individuals were not recounted. All individuals were released at their exact site of capture (uniquely marked with flagging tape) once the search was completed.

bles $(24 \%)$, pebbles $(8 \%)$, gravel $(12 \%)$, fines $(9 \%)$, leaf litter (4\%) and woody debris (3\%). Within both study areas, a narrow corridor of native vegetation borders both sides of the river, with adjacent hill slopes privately owned and subject to grazing by domesticated ungulates (sheep and cattle). However, the primary difference between the 2 rivers is that the Cotter River discharge is regulated to supply water to the city of Canberra, Australian Capital Territory, while the Goobarragandra is unregulated and displays natural fluctuations in discharge. During the sampling period (February to March 2009), we recorded a mean $( \pm \mathrm{SE}$ ) discharge rate of $59.8 \pm$ $2.0 \mathrm{Ml} \mathrm{d}^{-1}$, flow velocities of 0 to $36 \mathrm{~cm} \mathrm{~s}^{-1}$ and water temperatures of 20 to $22^{\circ} \mathrm{C}$ in the Goobarragandra River, compared to $2 \pm 0 \mathrm{Ml} \mathrm{d}^{-1}, 0$ to $49 \mathrm{~cm} \mathrm{~s}^{-1}$ and 20 to $22^{\circ} \mathrm{C}$ in the Cotter River.

Surveys of pool habitats (ranging from 8 to $24 \mathrm{~m}$ long, 2 to $5 \mathrm{~m}$ wide) for Euastacus armatus were made by observers actively searching on snorkel, deployment of baited remote underwater video cameras (Sony HDR-SRS high definition HDD in a perspex Ikelite 6038.91 underwater housing) and standard baited hoop nets (500 mm diameter top ring, $300 \mathrm{~mm}$ bottom ring, $400 \mathrm{~mm}$ depth between rings, $10 \mathrm{~mm}$ mesh size). All surveys were made during daylight hours (10:00 to $16: 00 \mathrm{~h})$, as E. armatus is a diurnally active species (Ryan et al. 2008). A single sampling occasion was conducted per method at each site, with a minimum of $2 \mathrm{~d}$ break between alternate sampling attempts at each site to minimise the influence of repeated sampling on subsequent detections.
BRUVS involved deploying 3 underwater video camera units approximately $15 \mathrm{~m}$ apart along a transect along the deeper sections of each site, for 2 stints of $1 \mathrm{hr}$ each, equating to the soaking period commonly used for hoop nets (Gilligan et al. 2007). After the first hour, the sampling gear was redeployed $5 \mathrm{~m}$ upstream of its original position. BRUVS were baited with a 1:1 mix of beef and chicken liver (mean $\pm \mathrm{SE}$ bait mass $74 \pm 3.9 \mathrm{~g}$ ), enclosed within a nylon stocking that was tied to 2 upright arms (100 mm length) on the metal bait plate, which was attached to an arm extending $500 \mathrm{~mm}$ out from directly below the video camera lens. Visible notches at $10 \mathrm{~mm}$ increments on the front edge of the bait plate and upright arms were used to calibrate measurements of the occipital carapace length (OCL) and cheliped length of crayfish (Fig. 2). Individuals observed near the BRUVS at the conclusion of the $2 \mathrm{~h}$ sampling session were hand netted and measured to validate size estimates from digital video analysis.

Baited hoop nets were deployed at the above sites as per the protocol for the BRUVS, except that the bait stocking was tied to the centre of the bottom hoop. During the hoop netting, all individuals caught in the first soak period $(1 \mathrm{~h})$ were removed and not returned to their capture location until the second soak period $(1 \mathrm{~h})$ was completed to ensure that only unique individuals were captured in each soak.

Captured Euastacus armatus were examined for gender and OCL, and cheliped length was measured to the nearest $0.1 \mathrm{~mm}$ using dial callipers. A small portion of the tail fan and the tip of the fifth pereopod 

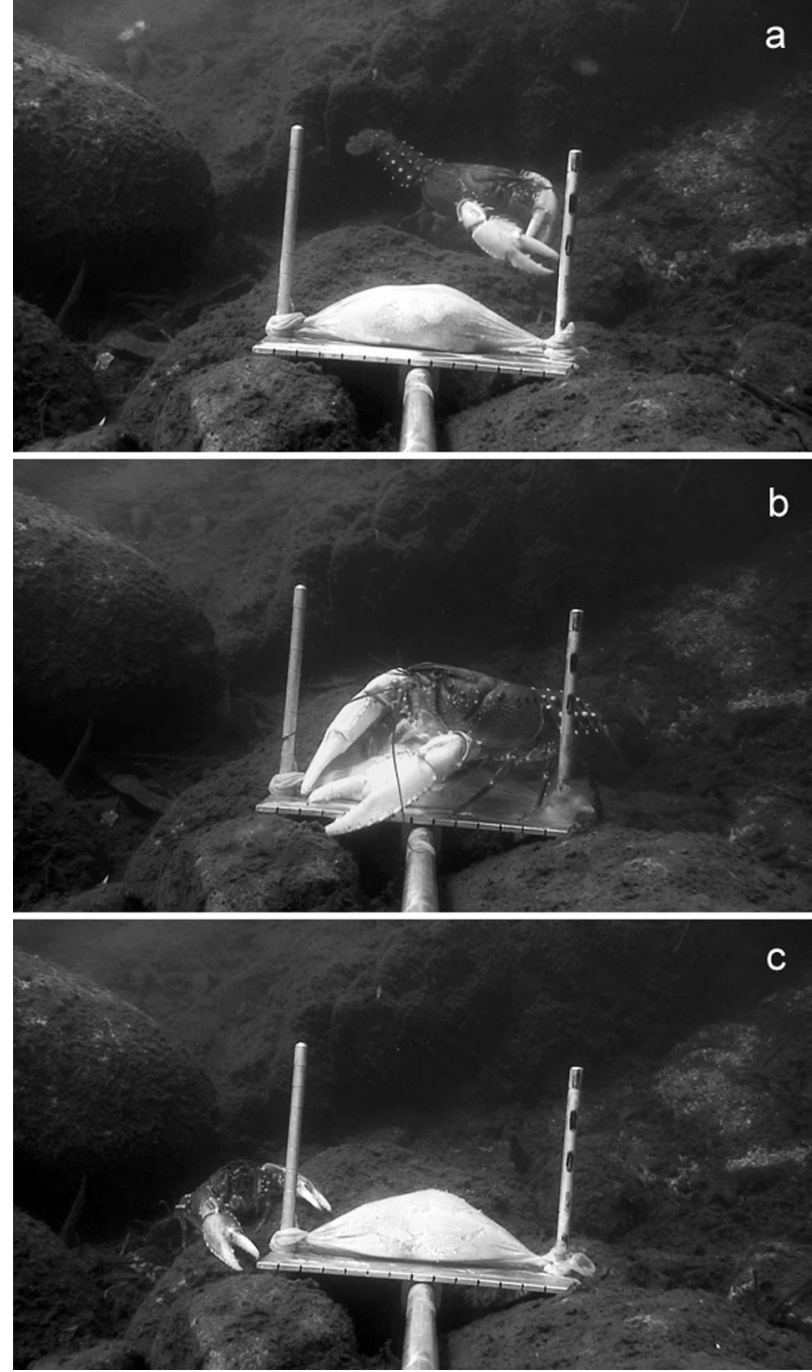

Fig. 2. Euastacus armatus. Individual (a) entering, (b) attempting to eat the bait and (c) leaving the frame of a baited remote underwater video survey (BRUVS). Estimated at $68 \mathrm{~mm}$ occipital carapace length (actual length: $66 \mathrm{~mm}$ ), this individual remained within frame for $205 \mathrm{~s}$

were clipped with scissors for individual identification. To compare the capture efficiency of the 3 sampling methods, capture rates were calculated as the total number of individuals caught or observed per hour for a standardised catch per unit effort (CPUE) estimate across all 3 methods. After a $\log _{10}(x+1)$ transformation of the CPUE data to minimise departures from normality and sphericity of variances (Mauchly's $W=0.389, \mathrm{p}>0.05$ ), a repeated measures analysis of variance (rANOVA) was used to detect within-subject differences in estimates of E. armatus population size via different survey technique (3 levels) employed within each of the 4 sites in the Goobarragandra River.

\section{RESULTS}

Both visual methods (active search and BRUVS) yielded similar numbers of Euastacus armatus individuals within the Goobarragandra River, and these visual estimates were 5 times greater than those recorded via hoop nets (Fig. 3a). Within the Cotter River, the only detection of E. armatus was via BRUVS (Fig. 3a). Average CPUE via visual methods was significantly higher than via hoop netting in the Goobarragandra River $\left(F_{2,6}=5.997, \mathrm{p}<0.05\right.$, Fig. 3b). While the small sample sizes of this rare species precluded any analysis of possible sex-related sampling biases, we did note a general lack of detection of small individuals across methods. While hoop nets and active visual surveys failed to detect any small $E$. armatus individuals (none $<40 \mathrm{~mm}$ OCL), BRUVS did record 1 very small individual ( 25 mm OCL) living sympatrically with an adult (63 mm OCL) in the Goobarragandra River. Notably, BRUVS-derived OCL measurements were within $3 \%$ of direct measurements of the known individuals. Most $(>70 \%) E$. armatus observations via BRUVS were made within 30 min after deployment (Fig. 4). Overall, individuals were within the field of view for an average $( \pm$ SE) of $139 \pm 70 \mathrm{~s}$ ( $\mathrm{n}=24$ observation periods), with the 7 individuals that made actual contact with the bait staying for longer time periods (mean $387 \pm 209 \mathrm{~s}$, maximum $1596 \mathrm{~s}$ ).

\section{DISCUSSION}

Disparate population estimates from varying survey methods can have serious implications for the monitoring and status assessment of species of conservation concern (Grand et al. 2007, McConville et al. 2009, Brooks et al. 2011). Here, we found distinct differences in relative abundance estimates achieved by 3 survey methods, with major differences between direct visual and hoop net methods. Indeed, when Euastacus armatus were rare, BRUVS was the only method to detect their presence. Our behavioural observations of crayfish from the underwater video footage also revealed that some individuals were cautious ('trap shy') of the baited methods, with most individuals staying on or near the hoop nets or camera bait plate for very short periods; such individuals are unlikely to be detected with baited hoop nets lifted at discrete, hourly intervals. Our observations are similar to previous studies of other crayfish species, which have found innate or learned aversions to sampling gear from compar- 

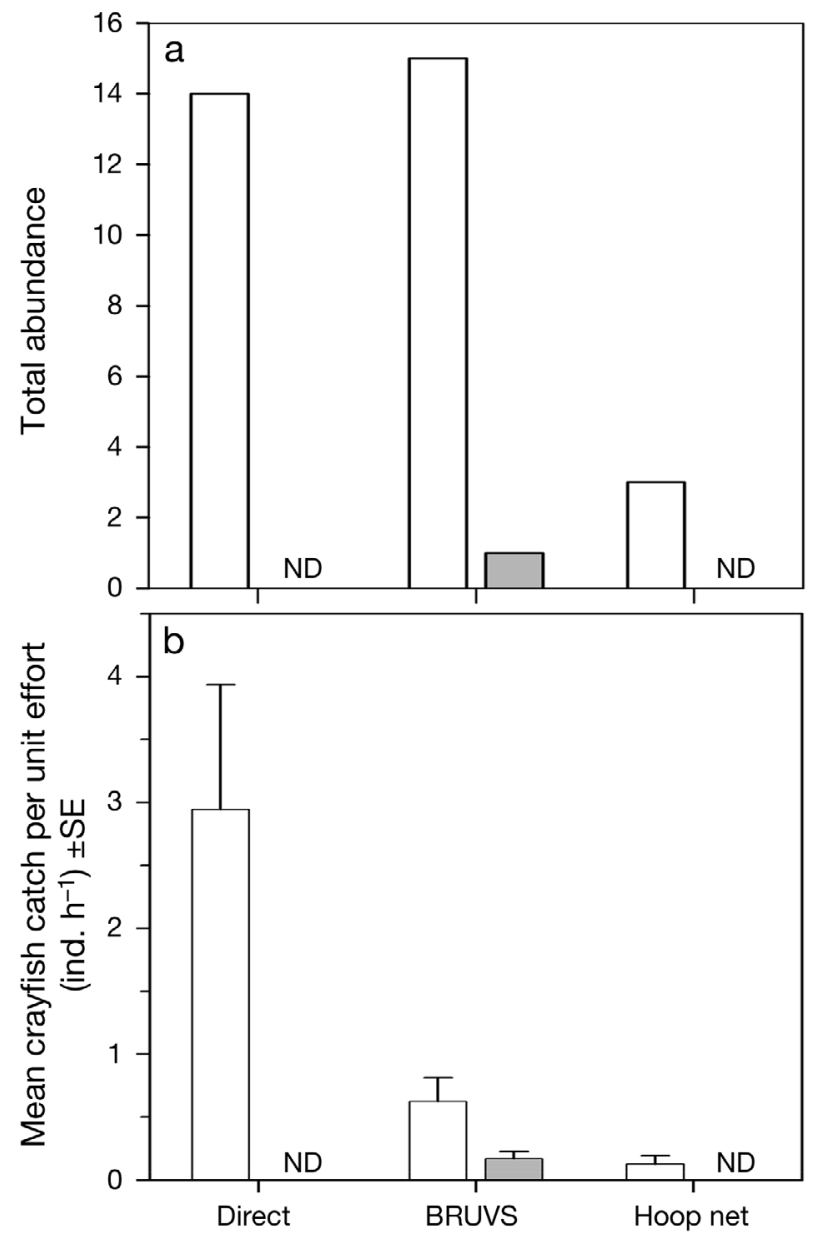

Fig. 3. Euastacus armatus. Comparative efficiency of direct visual survey (Direct), baited remote underwater video surveys (BRUVS) and hoop netting (Hoop net) methods for detecting freshwater crayfish across 4 sites on the Goobarragandra (white bars) and Cotter (grey bars) rivers, southeast Australia: (a) total number of unique individuals detected, and (b) mean crayfish caught per unit of effort (CPUE) for each survey method. ND: no crayfish detected with that method at any of the Cotter River sites

isons of passive trapping methods versus direct visual surveys and electrofishing (Bean \& Huner 1978, Somers \& Stechey 1986, Rabeni et al. 1997, Gucu 2009, Gladman et al. 2010). Importantly, such differences in sampling efficiency can lead to markedly different abundance estimates for a species, with the consequence that monitoring and conservation decisions are based on erroneous population estimates. Our results suggest that traditional hoop net methods can substantially underestimate E. armatus abundance; visual methods could provide a more effective and efficient means of measuring the presence and distribution of this elusive species in clearwater lentic and lotic ecosystems.

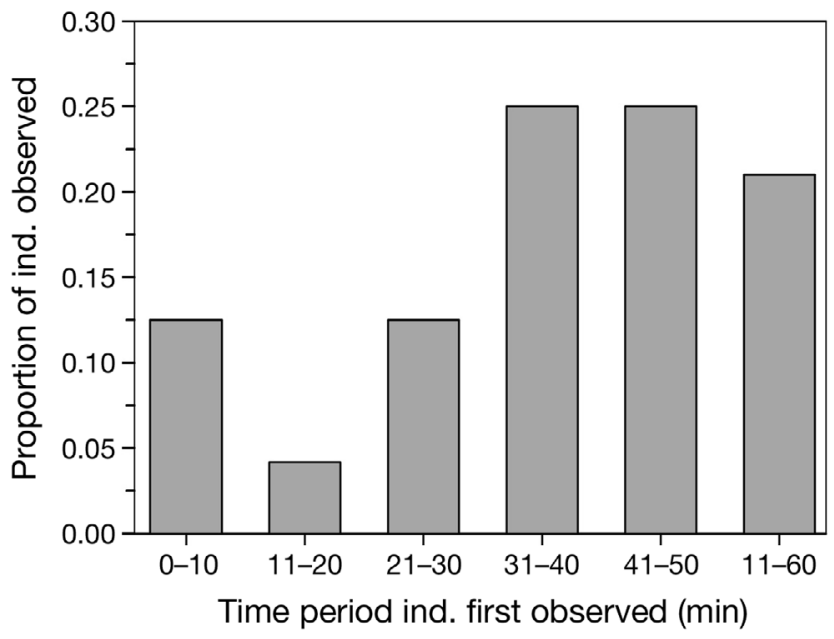

Fig. 4. Euastacus armatus. Frequency distribution of the time crayfish individuals ( $\mathrm{n}=24$ observations) entered the field of view in a standard $1 \mathrm{~h}$ session of baited remote underwater video surveys (BRUVS) footage. Proportions are calculated from pooling observations across all BRUVS footage taken across the 4 sites ( 3 cameras, $2 \mathrm{~h}$ each per site) on both Goobarragandra and Cotter rivers. Multiple observations of the same individuals $(\mathrm{n}=2$ individuals surveyed at least twice) are included

Comparatively, both visual survey methods have advantages and disadvantages for surveying crayfish in upland freshwater environments. Covering a large area in a short period of time, the active visual survey provided rapid detection of an equivalent number of individuals to the passively stationed underwater cameras. By contrast, the passively stationed baited cameras required longer periods to attract and survey all of the individuals in a given river section, plus additional laboratory time to analyse footage. While size estimates could be obtained from both BRUVS and direct surveys, information such as gender and reproductive status could only be recorded from direct visual surveys. Spatial separation for density estimates (ind. $\mathrm{m}^{-2}$ ) and microhabitat selection could also be recorded from direct visual surveys, while such measurements via baiting methods such as BRUVS is problematic unless the area of attraction is known (Acosta \& Perry 2000, Brooks et al. 2011). BRUVS can yield important behavioural information, such as intra- and interspecific competitive interactions between crayfish and other aquatic species (Bubb et al. 2006, Ebner et al. 2009). Finally, only moderate training of personnel is required in the visual surveys (specifically with size estimation). A limitation of the active visual surveys is that they require very good water clarity for adequate detection of all individuals. As such, this visual survey 
method may not be applicable across the full distribution of Euastacus armatus, which also occurs in high-turbidity environments present in the major rivers of south-east Australia. Indeed, this is a primary reason for the widespread use of hoop nets in previous surveys of the species (Gilligan et al. 2007).

Both the visual and baited camera survey methods examined here are likely to be valuable for the wide majority of the 49 Euastacus species that are largely or wholly restricted to clearwater conditions in cool mountain streams (Merrick 1995, Furse \& Coughran 2011a), and the large proportion of the 540 crayfish species found in freshwater systems globally (Holdich 2002). Moreover, the underwater video cameras are also likely to present a valuable role in studying behaviours of shy or cryptic crayfish that can be difficult to investigate by other means (e.g. Martin \& Moore 2007, Ebner et al. 2009). In contrast to the direct visual survey, it was possible to adapt the baited camera method for low-visibility conditions in some parts of the Cotter River (e.g. 15 to $30 \mathrm{~cm}$ Secchi depth). By adjusting the distance between the bait plate and the camera lens to be within visible range, it was possible to detect crayfish individuals that approached the bait in a similar fashion to the way they would on a baited hoop net. We suggest further research to determine the limitations of these underwater visual surveys to detect crayfish under varying levels of water clarity.

The rarity of small (juvenile and sub-adult) individuals observed in the current study and previous surveys of Euastacus armatus has led to suggestions that small individuals do not occur within the same pools as larger individuals (Morgan 1986, Gilligan et al. 2007). Electrofishing of small E. armatus individuals in smaller-order streams supports this claim (Raadik et al. 2001, Gilligan et al. 2007). By contrast, we visually detected a small individual occurring in the same area as a large individual (detected during the same $1 \mathrm{~h}$ sampling period of video footage). While this is only a single observation, it suggests that the habitat requirements of juveniles may not differ from those of large individuals. Electrofishing was not examined in this study because of the risk of cheliped loss (Westman et al. 1979) and its consequent effects on growth, defense and the reproductive potential of individuals (Alonso 2001), which was considered inappropriate given the conservation status of the study species. The habitat requirements and occurrence of early life history stages should be a priority for future research.

We conclude that both direct and remote visual census methods show great promise as effective means of surveying freshwater crayfish such as Euastacus armatus in montane rivers or streams, yielding abundances and CPUEs up to 5 times higher than traditional hoop netting. These observations draw attention to the need to conduct detailed investigations of the accuracy and statistical power of the visual methods for monitoring populations in clearwater montane rivers and streams to ensure that reliable population estimates are obtained. We suggest that the effectiveness of hoop net sampling methods be reviewed if they are to be used in monitoring programmes that inform conservation efforts for threatened freshwater crayfish species. We also recommend a strategy based on the use of multiple sampling techniques and incorporating multiple sources of information on crayfish populations (cf. Zukowski et al. 2011). This should yield accurate information for the conservation of crayfish populations (Gladman et al. 2010, Brooks et al. 2011). Given the Threatened, Endangered or Critically Endangered status of many of the world's diverse freshwater crayfish (Taylor et al. 1996, Holdich 2002), the use of BRUVS and/or direct visual surveys should be considered imperative for obtaining estimates of abundance in low-turbidity habitats, following the successful adoption of similar non-invasive techniques in detecting a range of endangered and cryptic aquatic taxa around the world (Bellwood et al. 2006, Rajamani \& Marsh 2010, Rayment et al. 2011).

Acknowledgements. We thank M. Lintermans for helpful comments on field methods for surveying crayfish, A. Muir for BRUVS construction, T. Starrs and K. Byron for field assistance, $M$. Noble for the maps, 3 anonymous reviewers for helpful comments on the manuscript and the Australian National University and ACTEW Corporation for funding support (to C.J.F.). This work was conducted under approval from the NSW Department of Primary Industries Scientific Collection Permit No. P08/0091-1.2 and in accordance with The Australian National University guidelines for research with invertebrate animals. This research was conducted in Wiradjuri and Ngunnawal country.

\section{LITERATURE CITED}

Acosta CA, Perry SA (2000) Effective sampling area: a quantitative method for sampling crayfish populations in freshwater marshes. Crustaceana 73:425-431

Alonso F (2001) Efficiency of electrofishing as a sampling method for freshwater crayfish populations in small creeks. Limnetica 20:59-72

Baker J (2004) Endangered populations: the concept in practice. In: Hutchings P, Lunney D, Dickman C (eds) Threatened species legislation - is it just an Act? Royal Zoological Society of New South Wales, Mosman, p 82-87

Bean RA, Huner JV (1978) An evaluation of selected crayfish 
traps and trapping methods. Freshw Crayfish 4:141-152

Bellwood DR, Hughes TP, Hoey AS (2006) Sleeping functional group drives coral-reef recovery. Curr Biol 16: 2434-2439

> Brooks EJ, Sloman KA, Sims DW, Danylchuk AJ (2011) Validating the use of baited remote underwater video surveys for assessing the diversity, distribution and abundance of sharks in the Bahamas. Endang Species Res 13: 231-243

Brown DJ, Brewis JM (1978) A critical look at trapping as a method of sampling a population of Austropotamobius pallipes (Lereboullet) in a mark and recapture study. Freshw Crayfish 4:159-164

Bubb DH, Thom TJ, Lucas MC (2006) Movement, dispersal and refuge use of co-occurring introduced and native crayfish. Freshw Biol 51:1359-1368

> Clarke RH, Oliver DL, Boulton RL, Cassey P, Clarke MF (2003) Assessing programs for monitoring threatened species - a tale of three honeyeaters (Meliphagidae). Wildl Res 30:427-435

> Dorn NJ, Urgelles R, Trexler JC (2005) Evaluating active and passive sampling methods to quantify crayfish density in a freshwater wetland. J N Am Benthol Soc 24: 346-356

Ebner B, Clear R, Godschalx S, Beitzel M (2009) In-stream behaviour of threatened fishes and their food organisms based on remote video monitoring. Aquat Ecol 43: 569-576

Fox RJ, Bellwood DR (2008) Remote video bioassays reveal the potential feeding impact of the rabbitfish Siganus canaliculatus (f: Siganidae) on an inner-shelf reef of the Great Barrier Reef. Coral Reefs 27:605-615

> Fulton CJ, Bellwood DR, Wainwright PC (2001) The relationship between swimming ability and habitat use in wrasses (Labridae). Mar Biol 139:25-33

Furse JM, Coughran J (2011a) An assessment of the distribution, biology, threatening processes and conservation status of the freshwater crayfish, genus Euastacus (Decapoda: Parastacidae), in continental Australia. II. Threats, conservation assessments and key findings. Crustac Monogr 15:253-263

Furse JM, Coughran J (2011b) An assessment of the distribution, biology, threatening processes and conservation status of the freshwater crayfish, genus Euastacus (Decapoda: Parastacidae), in continental Australia. I. Biological background and current status. Crustac Monogr 15:243-252

Geddes M (1990) Crayfish. In: Mackay N, Eastburn D (eds) The Murray. Murray-Darling Basin Commission, Canberra, p 302-307

Gilligan D, Rolls R, Merrick J, Lintermans M, Duncan P, Kohen J (2007) Scoping the knowledge requirements for Murray crayfish (Euastacus armatus). NSW Department of Primary Industries, Narrandera

Gladman ZF, Yeomans WE, Adams CE, Bean CW and others (2010) Detecting North American signal crayfish (Pacifastacus leniusculus) in riffles. Aquat Conserv 20: 588-594

Grand J, Cummings MP, Rebelo TG, Ricketts TH, Neel MC (2007) Biased data reduce efficiency and effectiveness of conservation reserve networks. Ecol Lett 10:364-374

Gucu AC (2009) Preliminary study on the effects of photo traps used to monitor Mediterranean monk seals Monachus monachus. Endang Species Res 10:281-285 Harvey ES, Newman SJ, McLean DL, Cappo M, Meeuwig
JJ, Skepper CL (2012) Comparison of the relative efficiencies of stereo-BRUVs and traps for sampling tropical continental shelf demersal fishes. Fish Res 125-126: $108-120$

Holdich DM (2002) Biology of freshwater crayfish. Blackwell Science, Cornwall

IUCN (International Union for Conservation of Nature) (2011) IUCN Red List of Threatened Species. 2011.2. IUCN, Gland

Martin AL III, Moore PA (2007) Field observations of antagonism in the crayfish, Orconectes rusticus: shelter use in a natural environment. Ethology 113:1192-1201

McCarthy B (2005) Distribution of Murray crayfish (Euastacus armatus) in the Mallee Region 2004. Murray-Darling Freshwater Research Centre, Mildura

McConville AJ, Grachev IA, Keane A, Coulson T, Bekenov AB, Milner-Gulland EJ (2009) Reconstructing the observation process to correct for changing detection probability of a critically endangered species. Endang Species Res 6:231-237

McCormick RB (2008) The freshwater crayfish of NSW Australia. BookPal, Coopers Plains

Merrick JR (1995) Diversity, distribution and conservation of freshwater crayfishes in the eastern highlands of New South Wales. Proc R Soc NSW 115:247-258

Morgan GJ (1986) Freshwater crayfish of the genus Euastacus Clark (Decapoda, Parastacidae) from Victoria. Mem Mus Vic 47:1-57

Raadik TA, O'Connor JP, Mahoney JC (2001) Fish and decapod crustacean survey. Regional Forest Agreement Process, Victoria, 1997 to 1999. Victorian Department of Natural Resources and Environment, Arthur Rylah Institute for Environmental Research, Heidelberg

Rabeni CF, Collier KJ, Parkyn SM, Hicks BJ (1997) Evaluating techniques for sampling stream crayfish (Paranephrops planifrons). NZ J Mar Freshw Res 31:693-700

Rajamani L, Marsh H (2010) Using parallel regional- and local-scale initiatives to inform conservation management of rare wildlife: a case study of the dugong Dugong dugon in Sabah, Malaysia. Endang Species Res 13:17-23

Rayment W, Dawson S, Scali S, Slooten L (2011) Listening for a needle in a haystack: passive acoustic detection of dolphins at very low densities. Endang Species Res 14: 149-156

Ryan KA, Ebner BC, Norris RH (2008) Radio-tracking interval effects on the accuracy of diel scale crayfish movement variables. Freshw Crayfish 16:87-92

Shields JM (2004) Threatened species legislation and threatened species recovery: Does the former lead to the latter? In: Hutchings $\mathrm{P}$, Lunney D, Dickman C (eds) Threatened species legislation-is it just an Act? Royal Zoological Society of New South Wales, Mosman, p 135-144

Somers KM, Stechey DPM (1986) Variable trappability of crayfish associated with bait type, water temperature and lunar phase. Am Midl Nat 116:36-44

Taylor CA, Warren ML Jr, Fitzpatrick JF Jr, Hobbs HH III, Jezerinac RF, Pflieger WL, Robison HW (1996) Conservations status of crayfishes of the United States and Canada. Fisheries 21:25-38

Westman K, Sumari O, Pursiainen M (1979) Electric fishing in sampling crayfish. Freshw Crayfish 4:252-255

Zukowski S, Curtis A, Watts RJ (2011) Using fisher local ecological knowledge to improve management: the Murray crayfish in Australia. Fish Res 110:120-127 